\title{
Relações de gênero, educação da pequena infância e mudanças políticas no Brasil: contribuições para um estado da arte*
}

\author{
Peterson Rigato da Silva ${ }^{1} * *$ \\ Tassio José da Silva ${ }^{2} * * *$ \\ Daniela Finco ${ }^{3} * * * *$
}

\section{Resumo}

Com o objetivo de atualizar o artigo já publicado em 2006 (Faria), este texto reúne pesquisas acerca das relações de gênero realizadas até 2016 e ainda esparsas na área da educação infantil. Tais estudos analisam as culturas infantis $e$ as relações de poder entre as meninas pequenas e os meninos pequenos de 0 a 6 anos, entre elas/es e entre elas/es e as/os profissionais docentes de creche e pré-escola. Nesse processo a luta feminista e os estudos de gênero contribuem substancialmente para as modificações no cotidiano da educação da pequena infância e na construção de uma pedagogia não sexista.

Palavras-chave: Pequena Infância, Movimento Feminista, Relações de Gênero, Educação Infantil, Creche e Pré-Escola.

${ }^{1}$ Recebido em 17 de junho de 2017, aceito em 01 de outubro de 2019.

** Diretor de Escola Municipal de Educação Infantil - EMEI, Piracicaba, SP, Brasil. Membro do grupo Gepedisc linha Culturas Infantis/Unicamp e IMAGO/UNESP. petersonrigato@gmail.com / https://orcid.org/0000-0001-80998912

${ }^{2}$ ***S Supervisor Pedagógico na Prefeitura Municipal de São Paulo, SP, Brasil. tassio.tato@hotmail.com / https://orcid.org/0000-0003-1907-6673

$3_{* * * *}$ Professora associada da Universidade Federal de São Paulo - UNIFESP. Líder do Grupo de Pesquisa Gênero, Educação da Pequena Infância, Cultura e Sociedade (Unifesp Guarulhos), Guarulhos, SP, Brasil. dfinco@unifesp.br / https://orcid.org/0000-0002-5731-1091 
Gender Relations, Early Childhood Education and Political Changes in Brazil: Contributions to a State of the Art

\begin{abstract}
To update an text published in 2006 (Faria), this article gathers studies on gender relations, conducted until 2016 and that are still rare in the field of early childhood education. These studies analyze the peer cultures and power relations among girls and boys up to 6 years old - both among the children, and between the children and teachers at daycare centers and preschools. In this process, the feminist struggle and studies of gender contribute substantially to modifications to early childhood education and to the construction of a non-sexist pedagogy.
\end{abstract}

Keywords: Early Childhood, Feminist Movement, Gender Relations, Early Childhood Education, Daycare Center and Preschool. 


\section{Apresentação}

A Josefina, professora de uma creche, estava entretida com um grupinho de crianças (a maioria delas com três anos de idade) que se travestiam das mais diferentes personagens. Algumas passavam batom, outras colocavam chapéu, cintos, capas, outras, sapatos de salto alto $e$ algumas meninas pediram para Josefina pintar-lhes as unhas da mão. De repente vem o Toninho e pede que ela pinte também as suas. Era a primeira vez que assim acontecia. Puxa, a professora ficou confusa, preocupada com o que as mães $e$ os pais pudessem achar disto $e$, para ganhar tempo, enquanto pensava como proceder perguntou para ele:

unhas?

- Você já pintou as unhas antes? Seu pai pinta as

E ele respondeu prontamente:

- Ah, eu nunca pintei antes. Meu pai não pinta também.

Bela resposta pensou, e eu, o que faço? Pergunto mais alguma coisa, quem sabe ele muda de ideia.

- De que cor você quer pintar?

E decidido Toninho responde:

- VER-ME-LHO.

E agora? Lá se foi meu emprego... Bom, mais uma pergunta, e quem sabe tudo se resolve.

- Mas por que vermelho?

E Toninho responde todo feliz

- É a cor do Schumacher! ${ }^{4}$

Pretendemos neste artigo discutir a questão complexa das relações de gênero e a primeira infância, bem como a construção de uma Pedagogia das diferenças de gênero ${ }^{5}$, apresentando pesquisas e alguns documentos oficiais que orientam a Educação

\footnotetext{
4 Este artigo foi escrito ampliando o artigo de Faria já publicado nos Cadernos Pagu em 2006. Por ela foi autorizado e agradecemos sua leitura crítica. Este episódio aqui relatado foi contado por uma ex-orientanda de Ana Lúcia Goulart de Faria, a quem agradecemos a autorização para reproduzi-la aqui; trata-se de uma história verdadeira, discutida em seu TCC e aqui adaptada para preservar a privacidade.

5 Hoje em dia já se nomeia Pedagogia das diferenças de gênero.
} 
Infantil brasileira. Pode-se falar em relações de gênero no contexto da Educação Infantil? ${ }^{6}$ Esta instigante pergunta acompanha as pesquisadoras e os pesquisadores feministas da pequena infância, hoje sistematizada numa sociologia da infância das diferenças de classe, gênero, idade e etnorracial. E também numa pedagogia da educação infantil que se funda nas culturas infantis produzidas pelas crianças entre elas e entre elas e os/as adultos/as no espaço e no tempo que constroem a condição infantil na esfera pública (Faria; Finco, 2011).

Assim, iniciaremos este texto homenageando as mulheres pesquisadoras que desde os meados dos anos de 1970, no interior dos movimentos feministas, vêm identificando o papel da infância na construção da realidade social, analisando o nexo entre autonomia e dependência nas atuais modificações sociais da gestão do tempo cotidiano. Enfim, conhecendo a criança pequena na esfera pública, em suas múltiplas manifestações, em que, no interior desse crescimento esquizofrênico da importância do valor da infância, permanece a rejeição de sua alteridade, isto é, da sua diversidade-diferença, do seu anarquismo e da sua libido perversa-polimorfa, do escândalo que provoca pela sua ligação muito forte com a natureza e a sua distância-estranheza em relação à cultura (Kuhlmann Jr., 1998).

Destacamos que, tanto na Itália como no Brasil, a creche "de outro tipo" nasce como direito trabalhista, produto da luta do movimento das mulheres, das feministas e sindicalistas, e posteriormente tornou-se um direito à educação e ao cuidado da criança.

Até há bem pouco tempo, considerava-se que as pessoas só começavam a ser a partir dos sete anos de idade, na escola obrigatória, para, ainda mais tarde, de fato serem capazes de fazer os raciocínios "superiores" quando já significava estar saindo da infância! Com o paradigma do "penso, logo existo", até havia seu

\footnotetext{
6 Interessante perceber que em algumas línguas, tais como o português (criança), francês (enfant), sueco (barn) e inglês (child), a palavra criança é sobrecomum e não declina o gênero no masculino e no feminino, como, por exemplo, em italiano (bambino, bambina) e em espanhol (niños, niñas).
} 
significado. Mas foi com as pesquisas recentes destes últimos quarenta e cinco anos que se passou a observar o que as crianças pequenas fazem quando estão entre elas num ambiente coletivo, organizado não por parentes, mas por profissionais adultos/as e/ou adultos/as com intencionalidade educativa, com ou sem diploma para o magistério, exercendo a função docente. Ainda com forte viés na Psicologia, essa pesquisa vai se tornando multidisciplinar, para a criança pequena para além da patologização, do higienismo, da incompletude, do apenas um vir-a-ser ${ }^{7}$, com contribuições da Antropologia, da Pedagogia da infância, da Sociologia da infância e outros campos que passam a pesquisar as crianças e as crianças pequenininhas, tal como a Geografia da infância.

É justamente o ingresso em massa das mulheres no mercado de trabalho e o movimento feminista que vão exigir creches para dividir com a sociedade a educação e o cuidado de seus filhos $e$ filhas, articulado aos movimentos no campo das esquerdas. Num primeiro momento, nos anos 70 a luta era por uma creche para as mulheres: "tenho direito de trabalhar, estudar, namorar e ser mãe. Sem creche não poderei usufruir de todos eles". No mundo ocidental, o prazer do convívio das crianças nas primeiras creches, chamadas selvagens, as italianas e as francesas, por exemplo, levou pesquisadoras/es a observarem como são as crianças entre elas quando estão fora da família, o que levará, nos anos 80 , à criação do movimento feminista, a levantar a bandeira também de creches, mas então para as crianças pequenininhas e não só para suas mães trabalhadoras ${ }^{8}$.

\footnotetext{
${ }^{7}$ Antes ainda, os países socialistas do chamado leste europeu já vinham fazendo essas pesquisas e divulgando as experiências, por exemplo, da escola não autoritária reichiana em Berlim, o Instituto Pikler, em Lóczy, na Hungria, com a palavra de ordem das crianças pequenininhas: "me deem tempo", "não tenho pressa de crescer", "me ensinem a fazer sozinho"

${ }^{8}$ Vale lembrar da bandeira nos anos 1980 do movimento de luta por creche na cidade de São Paulo (Brasil): "o filho não é só da mãe" e as consequências positivas pela primeira vez na Constituição de 1988 , que garantia o direito à educação $e$ ao cuidado em creche para os filhos e filhas de 0-6 anos de
} 
No Brasil, a primeira "Orientação Educativa" para a educação e o cuidado das crianças em creches não foi elaborada pelo MEC, mas pelo Conselho Nacional dos Direitos da Mulher (CNDM) e pelo Conselho Estadual da Condição Feminina (CECF), denominada Creche-urgente ${ }^{9}$. Esse material trouxe papel importante para a introdução do tema gênero na educação da primeira infância, junto com a ideia de creche enquanto uma instituição educativa na esfera pública, que fornece um espaço complementar à esfera privada da família para a criança, desde o nascimento. Os cinco cadernos Creche Urgente contribuíram para o debate e a instalação de um movimento amplo e nacional pela defesa de direitos da criança e da mãe, como cidadãs, sujeitos historicamente definidos e situados. E trazia propostas que indicavam direções para questões específicas a respeito da criança $e$ de suas necessidades e seus desejos. Assim, destacamos do referido documento um dos trechos que apresenta uma crítica feroz ao papel que é esperado da mulher na sociedade:

Historicamente, o fato de termos sido identificadas com as crianças, por um lado, e nossa característica de procriá-las, por outro, gera a falsa ideia de que isto é um "dom divino", "natural" e nos tem exigido muito trabalho, diferenciandonos dos homens negativamente. Como seres "inferiores", frágeis, e ao mesmo tempo maternos, sedutores, devemos cuidar das crianças, assim como dos homens, servindo-os como ama (Creche Urgente, 1987:08).

$\mathrm{O}$ mesmo documento questionou ainda a ideia de que a presença materna é a única alternativa de crescimento saudável para a criança, denunciou que a sociedade oferecia poucas instituições para a educação e o cuidado dos/as filhos/as e afirmou

trabalhadores e trabalhadoras, rurais e urbanos/as e posteriormente o direito do pai à licença paternidade.

9 Composto pelos seguintes cadernos: 1 Criança - compromisso social; 2 Organização e funcionamento; 3 Espaço físico; 40 dia a dia; 7 Relato de experiência. Os cadernos 5 e 6 não foram publicados. Versariam a respeito dos/as profissionais e recursos e financiamento. 
que as que existiam sofriam, naquela época, as influências assistencialistas, substituta precária da mãe ideal. O documento já afirmava que a presença da mãe não era a "única relação possível e saudável que a criança devia ter com o adulto", enfatizando a capacidade de a criança pequena estabelecer múltiplas relações. Apontou para a superação da concepção da creche como mal necessário, diante das novas necessidades e os desejos da mulher quando de sua inserção em massa no mercado de trabalho.

Além de questionar o papel das mulheres na sociedade, o documento Creche Urgente trouxe a concepção de criança benjaminiana, como "um pequeno cidadão do presente", destacando seus direitos, desejos e suas necessidades, como os de todo cidadão que vive e pensa o mundo. $\mathrm{O}$ documento defendia a "creche enquanto extensão do direito universal à educação da criança de 0 a 6 anos" enfatizando as desigualdades entre homens $e$ mulheres, pois propunha que as creches auxiliariam homens $e$ mulheres a se posicionarem de maneira diferente na educação de seus/suas filhos/as, dando direito a uma relação prazerosa, de troca e crescimento.

Tinha como foco o direito da mulher sobre seu próprio corpo, pois defendia que as "creches tornam-se uma opção de atendimento à criança pequena e à família". Isso favorecia a realização profissional docente e a participação social e política das mulheres, até então precariamente existente, em razão das atribuições decorrentes apenas do direito de ser mãe. E, finalmente, considerava a creche como instrumento de mudanças na realidade social, ao considerar que esse espaço poderia transformar as relações significativamente no tocante à interação adulto/a-criança, adulto/a-adulto/a e criança-criança.

Podemos afirmar que a Educação Infantil no Brasil nasceu como um instrumento emancipador das relações entre homens $e$ mulheres na sociedade. Esse fenômeno não pode ser esquecido quando pensamos no papel da profissional docente na Educação Infantil. Assim, o momento histórico da criação da creche, inserido nas ideias emancipadoras do movimento feminista, exerceu influência nas propostas educativas para a pequena infância, 
trouxe orientações acerca da importância de as crianças terem experiências variadas com diferentes crianças e adultos/as, de serem provocadas à experimentação, à imaginação, à invenção, à comunicação nas mais diferentes linguagens. Por isso, neste artigo destacamos o documento pioneiro brasileiro Creche Urgente, resultado do pensamento de vanguarda da luta feminista que, já no primeiro caderno, intitulado "Criança, compromisso social", traz uma proposta emancipatória para as crianças pequenas (Creche Urgente, 1987:14), e no que tange às questões de gênero:

Educar crianças reforçando as semelhanças entre meninos $e$ meninas significa formar cidadãos que cresçam sabendo que compartilham de um mesmo mundo, das mesmas tarefas e possibilidades. No processo educativo, as brincadeiras infantis não são neutras. Quando se oferece às meninas, basicamente, a opção de brincarem com panelinhas, bonecas, fogóes ou vassouras e aos meninos, aviões, bolas e correrias, estão sendo reforçados valores culturais que confinam as mulheres no plano doméstico $e$ os homens no espaço externo. Expressões como "isto não são modos de meninas" ou "meninos não choram" são formas de reforçar conceitos de feminilidade e de masculinidade, valores culturais que acentuam, no homem, características de agressividade, independência, força $e$ atividade; e na mulher, características de fragilidade, dependência docilidade e passividade. Nesta construção cultural do masculino e do feminino, que começa já desde a primeira infância, retira-se do ser humano a sua dimensão integral, resultante do convívio dialético, na mesma pessoa, de todas estas características.

O documento apontava para novos direitos das crianças e, não é por acaso, que a década da criança, anos 80, é posterior à década da mulher. Hoje conquistamos, já no papel, tanto o direito trabalhista dos trabalhadores/as para que seus filhos e filhas sejam educados/as em creches e pré-escolas, como o direito de todas as crianças de 0 a 6 anos serem, por opção de suas famílias, educadas fora da esfera privada, por profissionais docentes 
formadas/os para isso (e não para antecipar a escola obrigatória) ${ }^{10}$.

Atualmente, no mundo ocidental, a creche é considerada um patrimônio do feminismo, da esquerda e do sindicalismo dos anos 1970. Assim, com uma história completamente diversa da história da escola, a creche é um direito à educação também diferente. Ela é constituída por três atores: família/pais e mães, professoras/es e crianças ${ }^{11}$.

No Brasil, os Critérios de atendimento de uma creche que respeita os direitos fundamentais das crianças (Campos; Rosemberg, 1995) e os outros quatro cadernos dos "documentos das carinhas" 12 , a lei de Diretrizes e Bases da Educação Nacional e as Diretrizes Curriculares Nacionais para a Educação Infantil determinam que a Educação Infantil é a primeira etapa da

${ }^{10}$ Cabe esclarecer que são direitos conquistados na Constituição de 1988, mas que não são autoaplicáveis $e$, ainda hoje, não está definida a verba própria que garantirá sua aplicação. Em 1996, a Nova Lei de Diretrizes e Base da Educação Nacional define pela primeira vez na história do Brasil a Educação Infantil em creches e pré-escolas para as crianças de 0 a 6 de idade como a primeira etapa da Educação Básica (a segunda é o ensino fundamental e depois o ensino médio). Vale ressaltar a alteração na LDB em 2006, com a lei 11.274/2006, que passa as crianças de 6 anos para o Ensino Fundamental, uma perda para toda sociedade, já que as crianças deixarão de brincar, comprometendo assim a produção ilimitada das culturas infantis nessa etapa da educação básica, a Educação Infantil.

${ }^{11}$ A respeito dessa questão, o saudoso Enzo Catarsi (2013) destaca a importância das competências relacionais na constituição das relações entre a família/pais e mães, professoras e crianças no cotidiano da Educação Infantil.

${ }^{12}$ Cadernos elaborados pelo MEC no início dos anos de 1990 cujas capas tinham o desenho de carinhas de crianças negras, não negras, com olhos amendoados/puxados e várias diferentes aparências, revelando as diferenças entre as crianças brasileiras. Caderninho 1 Política Nacional de Educação Infantil. 2 Por uma Política de formação do profissional de Educação Infantil; 3 Critérios de atendimento de uma creche que respeita os direitos fundamentais das crianças (contém um vídeo muito instrutivo e muito bonito. Esse caderninho foi reeditado em 2009). 4 Proposta Pedagógica e curricular da Educação Infantil: um diagnóstico e a construção de uma metodologia de análise; 5 Educação Infantil: bibliografia anotada. 
Educação Básica, oferecida em creches e pré-escolas, as quais se caracterizam como espaços coletivos institucionais não domésticos, que constituem estabelecimentos educacionais na esfera pública, que educam e cuidam de crianças de 0 a 4 anos e 11 meses de idade no período diurno, em jornada integral ou parcial, regulados e supervisionados por órgão competente do sistema de ensino e submetidos a controle social.

Desta forma, articula o direito à educação das crianças pequenas com o direito trabalhista dos seus pais e mães. Nesse espaço da sociedade vivemos as mais distintas relações de poder: gênero, classe, idade e, lógico, étnicas. Ainda estão para serem melhor e mais estudadas e investigadas as relações no contexto da creche, em que se confrontam adultos - dentre eles, professor/a, diretora, cozinheira, porteiro, pai, mãe, secretário/a de educação, prefeito/a, vereador/a, etc. -; confrontam-se crianças, entre elas: menino, menina, mais velha, mais nova, negra, branca, judia, com necessidades especiais, pobre, rica, de classe média, católica, umbandista, candomblecista, ateia, "café com leite", "quatro olhos", etc; e adultos e crianças - a professora e as meninas, a professora e os meninos, o professor (percentual bastante baixo, mas existente e com tendência a lento crescimento) e os meninos, o professor e as meninas, o professor e a mãe da menina...

Os resultados das pesquisas na área educacional (embora não escolar), em espaços coletivos de educação e cuidado, têm mostrado que as crianças pequenas de 0 a 6 anos são capazes de múltiplas relações, são portadoras de histórias, de culturas infantis, são sujeitos de direitos. Ela é criança, além de ser filha referendada no adulto. Assim, a infância, que não se esgota aos seis anos de idade, é vista como uma fase da vida tão provisória (e concomitante) como as outras fases ${ }^{13}$. Destacam-se de forma híbrida as metodologias não convencionais para investigar a pequena infância, principalmente as pequenininhas, que não falam, não andam, não escrevem e não lêem as letras (numa

\footnotetext{
${ }^{13} \mathrm{Na}$ lei brasileira, o ECA - Estatuto da Criança e do Adolescente - estabelece a infância de 0 até os 12 anos de idade.
} 
sociedade grafocêntrica! adultocêntrica!): partem do princípio marxista: "o homem faz a história em condições dadas" (seja homem, mulher, adulto, jovem, velho, criança...). No entanto, a problematização com os novos atores sociais é colocada pela pós modernidade. Para além das classes sociais, as pequenas narrativas mostram também a história feita no âmbito das relações de poder entre homens e mulheres, negros e não negros, adultos $e$ crianças, etc.

A decana Egle Becchi (1983), da Universidade de Pavia (Itália), chama a atenção para o caráter suprainterpretativo da pesquisa com criança. Ela mostra o caráter interpretativo, por exemplo, na pesquisa acerca de mulheres: as outras mulheres que lerem os resultados podem discordar, debater, enfim, com as subjetividades aí explícitas (e implícitas também no tipo de infância que viveu o/a pesquisador/a), dependendo, inclusive, se a pesquisa foi realizada por homem ou por mulher.

No caso da pequena infância, a autora afirma diz que isso não será possível: as crianças pequenas não poderão ter esse tipo de participação, não são elas que interpretam. Assim, o rigor e a ética do/a pesquisador/as serão redobrados. Já nos disse Mário de Andrade: "menino, tu me recordas a minha presença em mim. E eu sofro".

Difundem-se diferentes ideias $e$ tradições intelectuais diversas dos estudos sobre a criança, o bom selvagem, a construção do indivíduo, o Iluminismo, o Romantismo, a criança na fábrica, o realismo socialista, a dupla alienação da infância ${ }^{14}$, o Expressionismo se estivéssemos falando em correntes artísticas, poderíamos asseverar que "as crianças são pop" ${ }^{15}$. E uma outra Pedagogia, como nos ensinam na Itália, portanto, se impõe: uma pedagogia da escuta, uma pedagogia das relações, uma

\footnotetext{
${ }^{14}$ Trata-se da concomitância nas sociedades contemporâneas que encurtam a infância, de infâncias privatizadas e de infâncias exploradas (Bertoni Jovine, apud, Faria, 2002). Impedidas, muitas vezes do direito de brincar com seus pares (embora as pesquisas demonstrem que as crianças transgridem).

${ }^{15}$ Expressão de uma professora de creche italiana no Festival de teatro para bebês em março de 2006, em Bologna.
} 
pedagogia das diferenças, e o que chamamos no Brasil de uma pedagogia macunaímica, pós-colonialista ${ }^{16}$. A Pedagogia, ciência da prática, busca suas bases epistemológicas em outras ciências (Freitas, 1985); no nosso ponto de vista, a arte é seu fundamento, garantindo, assim, a ausência de modelos rígidos preparatórios para a fase seguinte e, além de um cognitivismo característico das pedagogias, a construção de todas as dimensões humanas e o convívio com a diferença, "sem nenhum caráter" 17.

Eloísa Rocha (1999) elaborou um primeiro estado da arte das pesquisas (apresentadas em congressos nos anos 90 no Brasil) referente às crianças de 0 a 6 anos em creches e pré-escolas, e destacou a ausência das análises a respeito das relações de gênero e o reduzido número de pesquisas referentes às crianças pequenininhas de 0 a 3 anos. Nos últimos anos, essa situação não foi resolvida, mas, com certeza, foi amenizada num cenário complicado em que, segundo Rocha, apenas 3\% das pesquisas apresentadas nos congressos da ANPED (Associação Nacional de Pesquisa em Educação) analisaram as relações de gênero ${ }^{18}$.

\footnotetext{
${ }^{16}$ Os estudos pós-coloniais ajudam a pensar em uma pedagogia que questiona $e$ problematiza as diversas formas de colonialismo. Segundo Faria, Barreiro, Macedo, Santiago e Santos (2015, p. 16), "os estudos pós-coloniais, associados aos estudos da infância e da criança, buscam o rompimento com a forma androcêntrica e adultocêntrica de produzir ciência, desconfiando dos discursos estratégicos e arbitrários que, ao dissertarem sobre a infância, constituem suas próprias verdades".

17 "Pensando dessa forma, foi possível pensar a criança de uma maneira diferente das usuais: o fato de a criança não falar, ou não escrever, ou não saber fazer as coisas que os adultos fazem transforma-a em produtora de culturas infantis, justamente através "dessa(s)" especificidade(s). A ausência, a incoerência e a precariedade características da infância, em vez de serem "falta", incompletude, são exatamente a infância" (Faria, 1999, p. 77).

${ }^{18}$ Fúlvia Rosemberg (2001) também apresentou uma análise das pesquisas contemporâneas a partir das temáticas de educação e gênero, demonstrando um pequeno avanço dessas discussões em relação à década anterior. Esta constatação, segundo a autora, explica "pelo menos em parte, a pobreza das análises de situação, de agendas e de metas a serem atingidas no plano das políticas educacionais sob a ótica da igualdade de oportunidades de gênero" (2001:65).
} 
Acerca da pesquisa da pequena infância $e$ as relações de gênero na educação infantil, tanto em creches como em préescolas, estamos em uma trajetória promissora. Constatamos, na última década, um aumento significativo de pesquisas, publicações e eventos acadêmicos referentes ao debate das relações de gênero $e$ pequena infância que têm sido objeto de análise de pesquisadores e pesquisadoras de diferentes áreas do conhecimento, com destaque ao âmbito da educação.

As pesquisas apresentadas em seminários científicos ${ }^{19}$ revelaram a importância das instituições de educação infantil para a meta da construção de uma sociedade com oportunidades mais igualitárias. Assim, não podemos deixar de destacar o caráter emancipador das instituições de educação infantil, apresentado nas pesquisas: a contribuição das creches como espaços sociais $e$ políticos de efetivação de direitos e de construção de relações horizontais e igualitárias para as mais diferentes crianças pequenas, meninas e meninos, mulheres e homens.

Agora apresentaremos um panorama dessas pesquisas, de modo a contribuir para um estado da arte e potencializar as discussões a partir dos verbetes infância $e$ relações de gênero. Verificamos uma multiplicidade de procedimentos metodológicos que vem estruturando as pesquisas que problematizam gênero $e$ infância, com destaque para a Etnografia, que tem sido bastante utilizada. Vale lembrar que as crianças pequenininhas não falam,

\footnotetext{
${ }^{19}$ Por exemplo, recentemente, em 2014, realizamos o Simpósio Temático "Feminismo e Creche: desafios atuais para uma educação descolonizadora", no Seminário Internacional Fazendo Gênero 10 (UFSC, Florianópolis, Brasil), que trouxe como temática os desafios atuais dos feminismos. As discussões realizadas nesse simpósio resultaram no livro organizado por Finco; Gobbi e Faria, em 2015, intitulado: Creche e feminismo: desafios atuais para uma educação descolonizadora, Campinas: Edições Leitura Crítica, ALB, Fundação Carlos Chagas, 2015. A atual edição do Seminário Internacional Fazendo Gênero ocorrerá no mês de agosto do corrente ano de 2017, e constará do Simpósio temático organizado por Faria e Finco denominado: "Feminismo em estado de alerta na educação das crianças pequenas em creches e pré-escolas: deslocamentos, transformações e conexões emancipatórias para uma pedagogia descolonizadora".
} 
mas se comunicam com todas as outras linguagens $e$ a permanência do/da pesquisador/a no campo de pesquisa mostrase bastante apropriada, no sentido da captação de práticas, ocorrências e nas relações entre os meninos pequenos $e$ as meninas pequenas no contexto educativo, que, inevitavelmente, são permeadas por relações de gênero.

Nos documentos oficiais que organizam a Educação Infantil no Brasil, na gestão do presidente Lula e da presidenta Dilma (2003-2014), verificamos um alavancar das políticas públicas que colocam as crianças no centro do debate e da pedagogia, embora, para Santos (2014), as crianças continuam invisíveis, na medida em que muitas das publicações desses documentos ainda estão num processo inicial de discussão acerca das questões da diversidade na infância, dentre elas, gênero e raça. Também verificamos a presença da dicotomia sexo/gênero em diversas pesquisas e publicações, reverberando entre as diferentes interpretações binárias e antagônicas, geralmente calcadas numa perspectiva biologizante, patologizada, heteronormativa $e$ machista.

Pesquisas referentes às questões de gênero na educação de meninas pequenas e meninos pequenos, realizadas no Brasil, também investigam a presença dessas questões nos cursos de formação docente. Encontramos as discussões referentes às infâncias e a diversidade e a importância da Educação Infantil na (des)construção de estereótipos de gênero; também quando diz respeito à promoção de uma educação não sexista e que combata a inclusão excludente $e^{20}$ de toda origem. Destaca-se a tese de Drummond (2014), ao analisar o estágio curricular supervisionado no curso de Pedagogia da Universidade Federal do Tocantins, em

\footnotetext{
${ }^{20}$ A ideia problematiza por exemplo a cultura produzida nas instituições escolares, que ainda permanece fechada às diferenças, e que neste sentido nos faz urgente repensar este modelo de socialização que desconsidera os sujeitos em nome de uma suposta civilidade e universalização geradoras de uma "inclusão excludente" das crianças que estão fora dos padrões estabelecidos, o que nos leva a um questionamento do conceito de socialização até então vigente antes dos aportes da Sociologia da Infância (Oliveira, 2015).
} 
Miracema (Brasil). Ela enfatizou a importância das relações de gênero no processo de formação de professores e professoras, de modo a provocar os/as futuros/as docentes a observarem que as relações estabelecidas entre as crianças e entre as crianças e os adultos e adultas não são neutras, pelo contrário, são marcadas por preconceitos e estereótipos. Logo, essas interações, indubitavelmente, estruturam e marcam a produção das culturas infantis, muitas vezes sexista.

As interações protagonizadas por meninos $e$ meninas no cotidiano das creches e pré-escolas apontam que, por meio das brincadeiras, as crianças discutem os papéis e comportamentos considerados "naturais", além de refletir acerca dos brinquedos considerados certos ou errados para cada sexo, revelando as diversas transgressões protagonizadas pelas crianças no espaço coletivo, possibilitando novas formas de ser menino e de ser menina (Finco, 2004, 2010). Logo, como essas interações se organizam num espaço físico determinado, problematizar a organização e utilização desses espaços é importante, na medida em que detectamos um processo de espacialização pela ótica do gênero, ou seja, um movimento que objetiva separar e segregar meninos e meninas. Contudo, as interações vivenciadas pelas crianças na esfera pública enfatizam justamente o contrário: elas desejam estar juntas. E nesse processo transgridem e burlam as regras institucionais, na tentativa de experenciarem momentos juntos longe dos olhares dos adultos/as, como, por exemplo, nos banheiros (Silva, 2015).

Também nesta perspectiva, pesquisas acerca dos desenhos produzidos pelas crianças apontam para as construções culturais do feminino e do masculino, muitas vezes respeitando uma lógica de legitimação de estereótipos em torno das diferenciações de gênero. "Os estudos sobre a mulher, aliados à efervescência de movimentos sociais que criticavam as explicações biológicas sobre as diferenças $e$ desnaturalizavam formas de produção das desigualdades sociais e sexuais" (Gobbi, 2015:138). Isso possibilita olhar para as outras formas de hierarquização presentes nos espaços da educação das crianças pequenas, no sentido de 
quebrar com as relações de poder e pensar numa educação não sexista. Assim, os estudos de Gobbi $(1997,2015)$ apontam para as representações de gênero nos desenhos das crianças e também para novas configurações culturais, ou seja, para um processo de transição em que emergem novas formas de feminilidades $e$ masculinidades, como a mãe que ensina seu filho a lavar a louça $e$ ajudar nos trabalhos domésticos, pretendendo um masculino não machista e autônomo.

Schifino (2012) aponta que a luta por creches pelo movimento de mulheres demarca que a exigência das mães operárias em relação à educação de seus filhos e suas filhas está além da busca por um lugar para suas crianças ficarem enquanto trabalham, e sim da luta pelo direito à educação de qualidade.

Nesse sentido, a pesquisa de Schifino $(2012 ; 2015)$ mostra a luta por creche de duas gerações: mãe e avó da criança que frequenta a creche e ressalta que o "espaço específico de educação para as crianças pequenas, de qualidade, permite que a mulher exerça o trabalho em sua potencialidade, articulado à maternidade" (Schifino, 2015:72).

As pesquisas de Cruz (1998), Sayão (2005), Ramos (2011), Silva (2011), Monteiro (2014) e Silva (2014) a respeito de professores homens em creches e pré-escolas públicas apresentam a complexidade das docências quando se tem homens na educação de crianças pequenas, ou seja, existem diferentes masculinidades e feminilidades presentes entre os/as docentes no cotidiano das crianças pequenas, o que rompe com a ideia de uma única masculinidade ou feminilidade na educação infantil. A presença masculina aparece como um elemento de estranhamento em um local de educação ocupado predominantemente por mulheres, uma profissão que nasce feminina e que apresenta em seu bojo essências, características, ainda ditas "biológicas" da mulher. Não encontramos nenhuma pesquisa que tenha mostrado uma forma específica de docência masculina em creches e préescolas. Os homens pesquisados geralmente confirmam a tese de Saparolli (1997), de ser uma profissão de gênero feminino. 
Nesse sentido, ao se ter homens professores nos espaços da educação infantil, podemos observar, o que está vinculado ao complexo sistema das relações de poder e hierarquia que se encontra na construção da docência na educação infantil, uma profissão que está sendo inventada (Mantovani; Perani, 1999). Tais ambientes caracterizam e determinam a realidade presente de um determinado local, perpetuando ou não características do machismo e do sexismo (Silva, 2014).

A temática da hierarquização e diferenciação dos sexos vem sendo discutida desde a década de 1990 na educação infantil, aumentando o pequeno número de pesquisas que dão ênfase à trajetória de homens professores. Coloca-se em debate esse olhar que marca a divisão entre os sexos, olhar este que se pauta unicamente nas visões biológicas, dando destaque a diferentes formas de cuidado nos espaços educativos para as crianças pequenas.

Assim, no circuito das travessias e dos modos de dar visibilidade, destacamos outras pesquisas que buscam a intersecção gênero e raça. Silva (2011) traz as questões do homem negro professor de educação infantil e a intersecção entre gênero $e$ raça no âmbito do cuidado e na educação das crianças pequenas. Em suas pesquisas, o homem negro não cabe como professor de crianças pequenas, pois a figura do negro nos espaços da escola estava atrelada a outras funções (zeladoria, vigia). As pesquisas de Pereira (2012), Souza (2015) e Mendonça (2016) problematizam um modelo hegemônico de masculinidade, que se traduz ao binarismo masculino e feminino, legitima as desigualdades de gênero, o que possibilita refletir as dicotomias presentes nos espaços e tempos da educação de crianças pequenas e na desconstrução de uma visão binária da(s) identidade(s).

Nesse processo, alguns/mas os/as autores/as têm utilizado como ferramenta teórico-metodológica a interseccionalidade, pois acreditam que a multiplicidade das opressões não pode ser compreendida a partir da análise de uma única categoria. A dissertação de mestrado de Santiago (2014), ao problematizar a violência da hierarquização social capitalista, fundamentada no 
processo de racialização das crianças pequenininhas negras e não negras a respeito da construção das culturas infantis, já indicava a necessidade de pesquisas que considerem as interconexões entre racismo, classe, gênero, sexualidade, idade ou qualquer outro marcador social da diferença Porém, quando a temática é gênero, educação e cuidado dos bebês, ainda há lacunas nas pesquisas brasileiras. A questão vem sendo problematizada em pesquisas, apesar da carência de estudos que investiguem as crianças pequenininhas de 0 a 3 anos. Investigar gênero na relação dos bebês com as demais crianças e adultos/as ainda é uma temática a ser aprofundada.

Em pesquisa recente a respeito da participação dos bebês na luta de classes, Macedo (2016) ${ }^{21}$ apresenta a luta por creches pelo movimento de mulheres e feministas, bem como as relações desiguais entre homens e mulheres que perpassam os espaços $e$ tempos da educação das crianças pequenininhas, numa reflexão de uma educação emancipatória comprometida com a resistência ao sistema capitalista.

Neste sentido, podemos destacar também a importância da organização de tempos e espaços acolhedores que permitam maior interação entre os/as bebês, pois, segundo Faria (2000), a organização do espaço físico pode favorecer e ser favorecida por uma pedagogia das diferenças, das relações, da escuta, garantindo melhoria nas condições de vida pelo direito à educação das crianças de 0 a 6 anos.

\footnotetext{
${ }^{21}$ A tese de doutorado de Elina Macedo (2016) explora a ideia da participação dos bebês na luta de classes trazendo como desafio sua condição infantil e de classe social. $\mathrm{O}$ estudo discute a participação das crianças na sociedade de classes e uma perspectiva emancipatória de educação pautada no conceito de omnilateralidade das obras de Karl Marx. As análises apontam para as polêmicas categorias: a divisão sexual do trabalho, a infância como minoria e as culturas infantis. Discute o adultocentrismo e a relação desigual de poder entre homens e mulheres, entre adultos/as e bebês/ crianças pequenininhas e assim propõe a construção sobre uma educação emancipadora comprometida com a resistência ao sistema capitalista desde o nascimento.
} 
A formação docente das educadoras, monitoras, auxiliares de educação $0^{22}$ é uma questão importante para a consolidação da pedagogia da educação infantil e das diferenças de gênero, respeitando os direitos das crianças pequenas e também do aprimoramento profissional dessas mulheres, em sua maioria, que atuam com crianças pequenininhas, embora haja um lento crescimento do número de homens atuando com essa faixa etária.

A contribuição da pesquisa de Búfalo (2009), expressa já no título Nem só de salário vivem as docentes de creche, apresenta outras reivindicações, como exigência da melhoria da formação docente, e outras questões igualmente relevantes que permeiam o trabalho cotidiano dessas profissionais docentes relacionadas à questão de gênero.

Neste sentido, procuramos destacar, neste artigo, um movimento em que a temática das relações de gênero, principalmente na pequena infância, esteve em pauta tanto no debate acadêmico, quanto nas políticas públicas. Mas não poderíamos finalizar estas reflexões sem antes apresentar uma denúncia em face de um movimento que vem ganhando força $e$ legitimidade no Estado Brasileiro, que, ancorado numa pauta conservadora, iniciou um processo de desmonte, já em meados de 2014, que tinha como objetivo a retirada do debate das relações de gênero no Plano Nacional de Educação.

Além disso, cabe enfatizar que, nos últimos dois anos, desde o impeachment da Presidenta Dilma Rousseff (2016), estamos vivendo lamentavelmente no Brasil um grande movimento de retrocesso nas políticas para igualdade de gênero. Houve retrocessos em direitos fundamentais que já estavam assegurados. Entre muitos retrocessos destacamos a extinção do Ministério das Mulheres, Igualdade Racial e Direitos Humanos; da Secretaria de Educação Continuada, Alfabetização, Diversidade e Inclusão (Secadi). É importante destacar que tais órgãos públicos eram responsáveis pela implementação de políticas educacionais

\footnotetext{
${ }^{22}$ No Brasil, cada rede municipal nomeia a profissional que atua com crianças de 0 a 3 anos de uma forma diferente.
} 
públicas de enfrentamento ao preconceito e à discriminação, para educar a sociedade para o respeito e a valorização da diversidade e para o combate à discriminação, ou seja, constituição de uma cultura dos direitos humanos, por meio da educação formal (Brasil, 2006; 2008).

As medidas impeditivas vêm, especificamente, de determinados grupos que, ancorados em valores conservadores, limitam e cerceiam os princípios universais da democracia, a exemplo do tratamento igualitário a todos $e$ a todas, independentemente de cor, sexo, orientação sexual e outros marcadores que nos singularizam socialmente. A primeira versão do Plano Nacional de Educação (2014) incluía a necessidade de superação das desigualdades educacionais, dentre elas as questões de gênero e de raça. Porém, o texto final aponta, de forma genérica, para o combate a todas as formas de discriminação, ocultando processos que legitimam preconceitos nos espaços educativos. Esse debate se estendeu a alguns estados e municípios brasileiros, que, após forte pressão também de grupos religiosos, excluíram o termo gênero de seus respectivos planos, negligenciando a importância dessa temática na constituição das identidades de meninas e meninos.

Outro fato importante que evidenciamos no Brasil, durante a elaboração deste texto, é uma profunda crise e perda dos direitos humanos, situação tensionada pelo crescimento de movimentos reacionários que, apoiados na atual conjuntura política e social, defendem um modelo ditatorial, agora sem militares. Logo, esses grupos contribuem significativamente para a manutenção de valores patriarcais machistas, sexistas $e$ homofóbicos. Tal fato pode ser verificado com o recente ressurgimento da "Marcha da família com Deus pela liberdade" (já ocorrida quando do golpe de 1964), agora nas ruas do centro de São Paulo, no ano de 2014, que tinha como mote, dentre outros, valores da família nuclear, heterossexual e burguesa ${ }^{23}$.

${ }^{23} \mathrm{O}$ modelo tradicional de família nuclear burguesa vem, ao longo do século passado, sendo substituída por novos arranjos familiares, questionando a estrutura tradicional da figura materna e paterna no seio de sua organização. 
Além das alterações no estatuto da família, que estabelece regras jurídicas para o tipo de grupo de pessoas que pode ser chamado de família, ou seja, apenas a união entre um homem $e$ uma mulher, a charge da Laerte ${ }^{24}$ é exemplar!

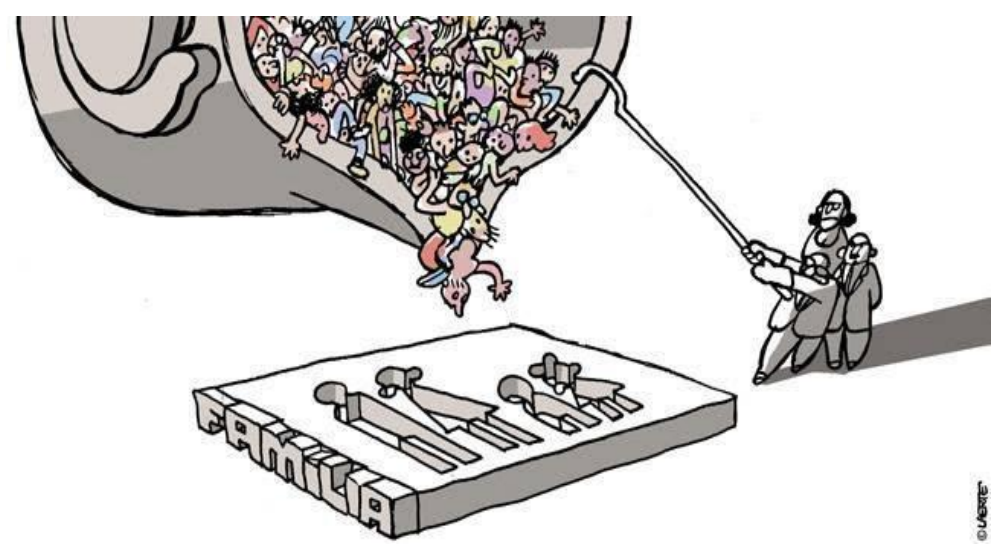

Diante do exposto, as pesquisas e os documentos discutidos neste artigo representam, efetivamente, a própria materialização da resistência e a contribuição acadêmico-científica, que não estão separadas das lutas dos movimentos sociais, na produção de conhecimentos para a construção de uma Pedagogia das diferenças de gênero para a educação $e$ o cuidado da primeira infância no Brasil.

Com os avanços desencadeados por meio das lutas dos movimentos feministas, a influência dos movimentos contraculturais da década de 1960 (Miskolci, 2007) e da organização da militância homossexual, passaram a se pautar para além das questões economicistas, reivindicando direitos e liberdades que tangenciavam suas identidades, suas manifestações afetivas e o direito ao prazer, desvinculando a sexualidade da reprodução e inferindo outras possibilidades de constituição familiar que não heterocentradas (Barreiro; Finco; Silva, 2015). Destacamos também uma lacuna no que diz respeito às pesquisas levantadas para este texto que discutam na creche e pré-escola a presença de casais homoafetivos.

${ }^{2421}$ Publicada na Folha de S. Paulo e autorizada e enviada para este artigo pela própria Laerte. 
O compromisso social, político e acadêmico, pela consolidação de um campo de estudos de gênero, com um longo trajeto de pesquisas que reúne reflexões que ainda nos revelam a permanência das desigualdades de gênero, articuladas às dimensões étnico raciais, etárias e de classe presentes na educação das crianças pequenas e pequenininhas, e que nos desafia a construção de ferramentas teórico-metodológicas a partir da interseccionalidade.

Finalizamos insistindo que a superação da desigualdade, com certeza, passa por uma educação emancipadora, desde o nascimento, em espaços coletivos na esfera pública como um lugar de confronto e convívio com as diferenças.

\section{Referências bibliográficas}

BARREIRO, Alex; FINCO, Daniela; SILVA, Tassio José da. Movimentos sociais LGBTT, mudanças e desafios para uma educação descolonizadora desde a infância. In: Vários Autores/Gepedisc Culturas Infantis (orgs). Infâncias e movimentos sociais. Campinas, SP: Edições Leitura Crítica, 2015, pp.151-166.

BECCHI, Egle. Molte infanzia, poche storie. Ricerche Pedagogiche, n. 689, Parma, 1983, pp.1-5.

BERTONI Jovine, Dina. L'educazione infantile in Italia. Scuola e Città. Roma, n.2-3, 1965.

BRASIL. Ministério da Educação. Constituição da República Federativa do Brasil - 1988. São Paulo: Saraiva, 1988.

BRASIL. Ministério da Educação. Governo Federal. Lei no 9.394, de 20 de dezembro de 1996: Lei de Diretrizes e Bases da Educação Nacional. Diário Oficial da União, Brasília.

BRASIL. Plano Nacional de Educação em Direitos Humanos: 2006/ Comitê Nacional de Educação em Direitos Humanos, em Direitos Humanos. - Brasília: Secretaria Especial dos Direitos Humanos, Ministério da Educação, Ministério da Justiça, UNESCO, 2006.

BRASIL. VI Relatório Nacional Brasileiro: Convenção pela Eliminação de todas as Formas de Discriminação contra as Mulheres CEDAW/Organizações das Nações Unidas. Brasîlia: SPM, 2008.

BRASIL. Política Nacional de Educação Infantil. MEC/SEF/COEDI, Brasilia, 1994. 
BRASIL. Educação Infantil: Bibliografia anotada. MEC/SEF/DPE/COEDI, Brasilia, 1994.

BRASIL. Por uma Política de formação do profissional de Educação. MEC/SEF/DPE/COEDI, Brasilia, 1994.

BRASIL. Critérios de atendimento de uma creche que respeita os direitos fundamentais das crianças. MEC/SEF/DPE/COEDI, Brasilia,1995.

BRASIL. Proposta pedagógica e currículo em Educação Infantil um diagnóstico e a construção de uma metodologia de análise. MEC/SEF/DPEF/COEDI, Brasília, 1996.

BUFALO, Joseane P. Nem só de salário vivem as docentes de creche: em foco as lutas do Sindicato dos Trabalhadores no Serviço Público Municipal de Campinas. Tese de doutorado, FE-Unicamp, 2009.

CAMPOS, Maria Malta; ROSEMBERG, Fúlvia. Critérios de atendimento de uma creche que respeita os direitos fundamentais das crianças. Brasilia: MEC/SEB/COEDI/FCC, Brasilia, 2009 (1995).

CATARSI, Enzo. As competências relacionais do professor na escola do acolhimento. In: STACCIOLI, Gianfranco. Diário do acolhimento na escola da infância. Campinas, SP: Autores Associados, 2013, pp.712.

CRECHE Urgente.1. Criança compromisso social. Conselho Estadual da Condição Feminina (CECF) e Conselho Nacional dos direitos da Mulher (CNDM). Brasilia, 1987.

CRECHE Urgente.2. Organização e funcionamento. Conselho Estadual da Condição Feminina (CECF), Conselho Nacional dos Direitos da Mulher (CNDM), Brasilia, 1988.

CRECHE Urgente 3. Espaço Físico Conselho Estadual da Condição Feminina (CECF), Conselho Nacional dos Direitos da Mulher (CNDM), Brasilia, 1988.

CRECHE Urgente. 4. O dia-a-dia. Conselho Estadual da Condição Feminina (CECF), Conselho Nacional dos Direitos da Mulher (CNDM), Brasília, 1988.

CRECHE Urgente.7. Relatos de experiências. Conselho Estadual da Condição Feminina (CECF), Conselho Nacional dos Direitos da Mulher (CNDM), Brasilia, 1988.

CRUZ, Elizabete Franco. Quem leva o nenê e a bolsa?: O masculino na creche. In: ARILHA, Margareth; RIDENTI, Sandra G. Unbehaum; MEDRADO, Benedito (orgs). Homens e masculinidades: outras palavras. São Paulo: ECOS; editora: 34, 1998, pp.49-67.

DRUMMOND, Viviane. Formação de professores e professoras de Educação Infantil no curso de Pedagogia: estágio e pesquisa. Tese de 
doutorado. Programa de Pós-Graduação em Educação, Universidade Estadual de Campinas, UNICAMP, 2014.

FARIA, Ana Lúcia Goulart de.

. A contribuição dos parques infantis

de Mário de Andrade para a construção de uma pedagogia da educação infantil. Educação e Sociedade, ano XX, nº 69, pp.60-91, Dezembro, 1999.

FARIA, Ana Lúcia Goulart de. O espaço físico como um dos elementos fundamentais para uma Pedagogia da Educação Infantil. In: FARIA, Ana Lúcia G.; PALHARES, Marina S. (Org.). A Educação Infantil pós LDB: rumos e desafios. Campinas, S.P.: Autores Associados, 2000, pp.67-96.

FARIA, Ana Lúcia Goulart de. Educação pré-escolar e cultura. 2.e.d. SP: Cortez, 2002.

FARIA. Ana Lúcia Goulart de. Pequena infância, educação e gênero no Brasil: subsídios para um estado da arte. Cadernos Pagu. pp.279287, jan/jun de 2006.

FARIA, Ana Lúcia Goulart de; FINCO, Daniela. (Org.). Sociologia da Infância no Brasil. Campinas-SP: Autores Associados, 2011.

FARIA, Ana Lúcia Goulart de; BARREIRO, Alex; MACEDO, Elina; SANTIAGO, Flavio; SANTOS, Solange. Invitações pós-coloniais. In: Infâncias e póscolonialismo: pesquisas em busca de pedagogias descolonizadoras. Campinas, SP: Leitura Crítica; Associação de Leitura do Brasil - ALB, 2015, pp.11-24.

FINCO, Daniela. Faca sem ponta, galinha sem pé, homem com mulher. relações de gênero nas brincadeiras de meninos e meninas na préescola. Dissertação de mestrado, Programa de Pós-Graduação em Educação, Universidade Estadual de Campinas, Unicamp, 2004.

FinCO, Daniela. Educação infantil, espaços de confronto e convívio com as diferenças: análise das interações entre professoras e meninas $e$ meninos que transgridem as fronteiras de gênero. Tese de doutorado, programa de pós-graduação em educação- USP, 2010.

FINCO, Daniela; SILVA, Peterson Rigato da; DRUMMOND, Viviane. Repensando as relações na educação infantil a partir da ótica de gênero. In: Vários Autores/Gepedisc Culturas Infantis (orgs). Culturas Infantis em creches e pré-escolas: estágio e pesquisa. Campinas-SP: Autores Associados, 2011, pp.59-85.

FREITAS, Luiz Carlos de. Notas Sobre a Especificidade do Pedagogo e sua Responsabilidade no Estudo da Teoria e Prática Pedagógicas. Educação e Sociedade, São Paulo, Cortez, n. 22, pp.12-19, 1985. 
GOBBI, Márcia Aparecida. Lápis vermelho é de mulherzinha: desenho infantil, relações de gênero e educação infantil. Dissertação (Mestrado) - Faculdade de Educação, Universidade Estadual de Campinas, Campinas, 1997.

GOBBI, Márcia Aparecida. Lápis vermelho é de mulherzinha: vinte anos depois. In: FINCO, Daniela; GOBBI, Márcia Aparecida; FARIA, Ana Lúcia Goulart de (orgs). Creche e feminismo: desafios atuais para uma educação descolonizadora, Campinas: Edições Leitura Crítica, ALB, Fundação Carlos Chagas, 2015, pp.137-162.

KuHLMANN Jr., Moysés. Infância e educação infantil - uma abordagem histórica. Porto Alegre: Mediação, 1998.

LAERTE, Coutinho. Família. Publicada pelo Jornal Folha de São Paulo.

MACEDO, Elina. Crianças pequenininhas e a luta de classes. Tese de doutorado. Programa de Pós-graduação em Educação, Universidade Estadual de Campinas, Unicamp, 2016.

MANTOVANI, Susanna; PERANI, Rita Montoli. Uma profissão a ser inventada: o educador da primeira infância. Pro-Posiçóes, v. 10, no 1 (28), pp.75-98, março de 1999.

MENDONÇA, Michelle Mariano. Impacto da presença de gestores e professores homens em centros de educação infantil: alguns elementos para compreensão. Dissertação de mestrado. Programa de Pós-graduação em Educação, PUC-SP, 2016.

MISKOLCI, Richard. Pânicos morais e controle social: reflexões sobre o casamento gay. In: Cadernos Pagu. Campinas: Núcleo de Estudos de Gênero Pagu - UNICAMP, n.28, pp.101-128, 2007.

MONTEIRO, Mariana Kubilius. Trajetórias na docência: professores homens na educação infantil. Dissertação de mestrado, Programa de Pós-graduação da Faculdade de Educação Física, Universidade Estadual de Campinas - UNICAMP, 2014.

OLIVEIRA, Fabiana. Infância e resistência: um estudo a partir das relac,ões étnico-raciais entre adultos e bebés nas creches. FARIA, Ana Lúcia Goulart de Faria; BARREIRO, Alex; MACEDO, Eliana Elias de; SANTIAGO, Flávio; SANTOS, Solange Estanislau dos. (Orgs). Infâncias e pós-colonialismo: pesquisas em busca de pedagogias descolonizadoras - Campinas, SP: Leitura Crítica; Associaçãa de Leitura do Brasil - ALB, 2015, pp.127-153.

PereIRA, Maria Arlete Bastos. Professor homem na educação infantil: a construção de uma identidade. Dissertação de mestrado, Programa de Pós-Graduação em Educação, UNIFESP, 2012. 
RAMOS, Joaquim. Um estudo sobre os professores homens na educação infantil e as relaçóes de gênero na rede Municipal de Belo Horizonte $M G$. Dissertação (mestrado em educação), Universidade Pontifícia Católica de Minas Gerais - PUC-MG, 2011.

RocHA, Eloisa. A pesquisa em educação infantil no Brasil - trajetória recente e perspectivas de consolidação de uma Pedagogia da educação infantil. Florianópolis, Editora da UFSC, 1999.

ROSEMBERG, Fúlvia. Caminhos cruzados: educação e gênero na produção acadêmica. Educação e Pesquisa, v.27, $\mathrm{n}^{\circ}$ 1, pp.47-68, jan./jun., 2001.

SANTIAGO, Flávio. O meu cabelo é assim... igualzinho o da bruxa, todo armado: hierarquização e racialização das crianças pequenininhas negras na educação infantil. Dissertação de Mestrado. Programa de Pós-graduação em Educação, Universidade Estadual de Campinas, Unicamp, 2014.

SANTOS, Solange Estanislau dos. As crianças (in)visiveis nos discursos políticos da Educação Infantil: entre imagens e palavras. Tese de Doutorado. Programa de Pós-Graduação em Educação, Universidade Estadual de Campinas, UNICAMP, 2014.

SAPAROLI, Eliana. Educador infantil: uma ocupação de gênero feminino. Dissertação (Mestrado em Educação) -Pontifícia Universidade Católica de São Paulo, São Paulo, 1997.

SAYÃO, Deborah T. Relações de gênero e trabalho docente na educação infantil: um estudo de professores de creche. Tese (Doutorado) CCE/UFSC, Florianópolis/SC, 2005.

SILVA, Claudionor Renato de. Professor homem, negro na escola da infância: reflexões e apontamentos de um iniciante. Temas em educação e saúde, Araraquara-SP: UNESP, v. 7, pp. 125-150, 2011.

SILVA, Peterson Rigato da. A presença masculina na educação infantil: diversidade e identidades na docência. In: FARIA, Ana Lúcia Goulart de; FINCO, Daniela (orgs). Sociologia da Infância no Brasil. Campinas: Autores Associados, 2011, pp. 105-120.

Silva, Peterson Rigato da. Não sou tio, nem pai, sou professor! $A$ docência masculina na Educação Infantil. Dissertação de Mestrado, Programa de Pós-graduação em Educação, Universidade Estadual de Campinas - Unicamp, 2014.

SILVA, Tássio José da. Organização e utilização dos espaços físicos na Educação Infantil: um estudo sob a ótica do gênero. Dissertação de Mestrado, Programa de Pós-Graduação em Educação, Universidade Federal de São Paulo - UNIFESP, 2015. 
SOUZA, José Edilmar de. Homem docência com crianças pequenas: olhar das crianças de um centro de educação Infantil. $37^{a}$ Reunião Nacional da ANPED, 04 e 08 de outubro de 2015, UFSC Florianópolis.

RochA, Eloisa Acires Candal. As pesquisas sobre educação infantil no Brasil: A trajetória na ANPED (1990-1996). Pro-Posiçôes - v. 10, n¹ (28), pp.54-74, março de 1999.

SCHIFINO, Reny Scifoni. Direito à creche: um estudo das lutas das mulheres operárias no município de Santo André. In: FINCO, Daniela; GOBBI, Márcia Aparecida; FARIA, Ana Lúcia Goulart de (orgs). Creche e feminismo: desafios atuais para uma educação descolonizadora, 2015, pp.57-78.

SCHIFINO, Reny Scifoni Direito à creche: um estudo das lutas das mulheres operárias no município de Santo André. Dissertação de mestrado, Programa de Pós-graduação em Educação, Unicamp, 2012. 